\title{
FORMAÇÃO DE PROFESSORES PARA O ENSINO DE MATEMÁTICA NOS ANOS INICIAIS DO ENSINO FUNDAMENTAL I
}

\author{
THAYRES SARMENTO SÁ \\ Universidade Federal de Campina Grande - UFCG \\ thayresarmento@hotmail.com \\ LUCIELMA ABRANTES RIBEIRO DE FREITAS \\ Universidade Federal de Campina Grande - UFCG \\ lucielmaabrantes@gmail.com \\ APARECIDA CARNEIRO PIRES \\ Universidade Federal de Campina Grande - UFCG \\ acppedagoga@yahoo.com.br
}

\begin{abstract}
RESUMO
O presente artigo tem por objetivo geral compreender a relevância da formação para a prática pedagógica dos educadores com ênfase na Matemática dos anos iniciais do Ensino Fundamental I. No qual, se irá ressaltar os desafios que existe frente à formação do professores para o ensino da matemática, que os docentes enfrentam. Além, da aula já que, a maioria dos discentes não gostam de Matemática, considerando-a como uma disciplina difícil. Diante disso, a questão de pesquisa incorreu a partir da indagação: Qual a formação dos professores para trabalharem com o ensino da Matemática nos anos iniciais do Ensino Fundamental I articulado com sua pratica pedagógica para despertar no discente o interesse em estudar matemática? Fundamentou-se pelo o estudo dos principais autores como: NACARATO (2009), MACCARINI (2010) e TOLEDO (2009). É necessário ainda que, tanto a parte teórica como a prática para o professor de matemática, auxiliando-o assim, desde a apresentação dos conteúdos de forma que incentive a participação e interesse da turma pela Matemática, além de torná-la uma disciplina importante para viver em sociedade e a formação continuada que ofereça o aprimoramento da ação docente.
\end{abstract}

PALAVRAS-CHAVE: Formação de Professores. Ensino de matemática. Anos Iniciais do Ensino Fundamental I.

TEACHER TRAINING FOR MATHEMATICS TEACHING IN THE INITIAL YEARS OF FUNDAMENTAL EDUCATION I

\begin{abstract}
The purpose of this article is to understand the relevance of training to the pedagogical practice of Mathematics Teachers in the initial years of Elementary School I. In this paper we will highlight the challenges that exist in teacher education for mathematics teaching, Which teachers face. In addition, from the class since, most of the students do not like math, considering unfortunately as a difficult discipline. Faced with this, the question of research was based on the question: What is the training of teachers to work with the teaching of
\end{abstract}


Mathematics in the early years of Elementary School I articulated with their pedagogical practice to awaken in the student the interest in studying mathematics? It was based on the study of the main authors as: NACARATO (2009), MACCARINI (2010) and TOLEDO (2009). Therefore, it is necessary that the teacher of Mathematics has an initial formation consistent with theoretical and practical foundation that facilitates the presentation of the contents in a way that encourages the participation and interest of the class by Mathematics making it an important discipline to live in society and Continuing education that offers the improvement of the teaching activity.

Keywords: Teacher Training; Mathematics teaching; Early Years of Elementary School I;

\section{FORMACIÓN DE PROFESORES PARA LA ENSEÑANZA DE MATEMÁTICA EN LOS AÑOS INICIALES DE LA ENSEÑANZA FUNDAMENTAL I}

\section{RESUMEN}

El presente artículo tiene por objetivo general comprender la relevancia de la formación para la práctica pedagógica de los educadores de la Enseñanza de Matemáticas de los años iniciales de la Enseñanza Fundamental I. En el que se resaltar los desafíos que existe frente a la formación del profesorado para la enseñanza de las matemáticas Que los docentes enfrentan. Además, de la clase ya que, la mayoría de los estudiantes no les gusta Matemáticas, considerando lamentablemente como una disciplina difícil. En este sentido, la cuestión de la investigación ha incurrido en la indagación: Cuál es la formación de los profesores para trabajar con la enseñanza de la Matemática en los años iniciales de la Enseñanza Fundamental I articulado con su práctica pedagógica para despertar en el discente el interés en estudiar matemáticas? Se fundó por el estudio de los principales autores como: NACARATO (2009), MACCARINI (2010) y TOLEDO (2009). Por lo tanto, es necesario que el profesor de Matemáticas tenga una formación inicial consistente con fundamentación teórica y práctica que facilite la presentación de los contenidos de forma que incentive la participación e interés de la clase por la Matemática haciéndola una disciplina importante para vivir en sociedad y la Formación continuada que ofrezca el perfeccionamiento de la acción docente.

Palabras clave: Formación de profesores. Enseñanza de matemáticas. Años iniciales de la enseñanza primaria I.

\section{INTRODUÇÃO}

Atualmente, a sociedade está em constantes mudanças, seja na área tecnológica, educacional, econômico, cultural e política. No meio de tantas transformações e inovações está à escola, sendo o reflexo de intervenções na vida do sujeito. Neste sentido, a escola pode auxiliar através de ações educativas o indivíduo a construir sua cidadania e ter acesso ao mercado de trabalho, oferecendo atividades que proporcione reflexões críticas ajudando-o a transcender os muros escolares. Deste modo, é atribuído a escola o compromisso e a 
obrigação de adaptar-se a tais mudanças utilizando estratégias metodológicas que auxiliem o educando a viver como ser atuante em sociedade.

Sendo assim, é primordial ressaltar que cada método de ensino tem suas particularidades, em consonância com a realidade e contexto social que cada sujeito está inserido. Neste sentido, falar sobre formação de professores para o ensino da Matemática nos anos iniciais do Ensino Fundamental I é um desafio, já que, o processo de formação de professores não é algo fixo, mas que está em constante aperfeiçoamento, seja através de uma leitura de um livro, palestra, formação continuada, no intuito de aprimorar a prática docente em sala de aula, fazendo com que o educando seja motivado a aprender matemática.

Diante disso, o presente estudo tem como objetivo geral compreender a relevância da formação para a prática pedagógica dos educadores do Ensino de Matemática dos anos iniciais do Ensino Fundamental I, em prol de despertar o interesse no educando de aprender diariamente sobre e com a matemática, neste sentido, o estudo originou-se a partir de discussões durante as aulas da disciplina curricular de Fundamentos e Metodologias do Ensino da Matemática do curso de Licenciatura em Pedagogia, da Unidade Acadêmica de Educação do Centro de Formação de Professores, UFCG- campus de Cajazeiras-PB. Além disso, proporciona algumas discussões sobre a formação de professores, como também, ressaltar a importância do ensino de matemática na vida do sujeito, em seu contexto pessoal e social.

Ademais, é necessário fazer-se reflexões sobre as práticas, estratégias e metodologias desenvolvidas pelo educador de Matemática em sala de aula, analisando se suas práticas oferecem contribuições para a formação pessoal, profissional e social do sujeito em sociedade.

Para ampliar essa compreensão a parte empírica do estudo aqui abordado, teve como eixo principal uma pesquisa bibliográfica, na qual foi possível a leitura de livros, leis e artigos que tratam da formação de professores tendo como foco o ensino da matemática nos anos iniciais do ensino fundamental I e, suas ações educativas que refletirão nos discentes, dando ainda todo suporte necessário para a excelência na discussão aqui empreendida. Entretanto, na intenção de delimitar a discussão do tema aqui proposto, trabalhou-se com a seguinte questão de pesquisa: Qual a formação dos professores para trabalharem com o ensino da Matemática 
nos anos iniciais do Ensino Fundamental I articulado com sua pratica pedagógica para despertar no discente o interesse em estudar matemática?

Assim, irão ser disponibilizadas algumas reflexões para que essa indagação seja analisada e apresentada no decorrer do estudo, afim de contribuir com o ensino da matemática que nos dias atuais, o qual ainda é visto como uma disciplina difícil de estudar e aprender, além de trazer a formação de professores teórico e prático como um artificie que subsidiará essa etapa com avanços na área do ensino da matemática, transcendendo os limites da sala de aula.

Além disso, o referido trabalho teve como principais autores fundamentando-o, NACARATO (2009), MACCARINI (2010) e TOLEDO (2009).

Todavia é imprescindível que, o educando observe a Matemática como instrumento necessário e indispensável para a formação do sujeito enquanto ser social, mas para que, esse processo ocorra com êxito é fundamental a participação e formação dos docentes para que em sua atuação haja um ensino de qualidade no âmbito da matemática, propiciando aprendizagens significativas.

\section{A FORMAÇÃO PROFISSIONAL DO DOCENTE PARA O ENSINO DE MATEMATICA}

Inicialmente é importante ressaltar que, o ensino de Matemática tem sido enfrentado pela escola pública como um desafio, uma vez que, está interligado também ao ato de aprender e ensinar matematicamente, devido muitos docentes não terem uma formação adequada para este ensino os discentes sentem-se desmotivados por enxergarem a matemática como uma disciplina difícil e cansativa, já que exige muito do raciocínio lógico e prático. Trata-se de questões pelas quais o/a educador/a necessita de uma formação qualificada, para aprimorar a sua prática educativa, utilizando metodologias que anulem o paradigma de que a "matemática é uma disciplina difícil; nada sei sobre matemática" e passando a vê-la como algo indissociável da vida do sujeito.

É evidente que, com as reformas curriculares o ensino da Matemática avançou trazendo consigo, novas formas de ensino. Em consequência disso, Nacarato (2009, p.17) apresenta pontos positivos como, “o reconhecimento da importância do raciocínio combinatório, para o 
ensino da matemática escolar é preparar o cidadão para uma atuação na sociedade em que vive”, ou seja, a matemática está constantemente presente na vida do sujeito de diversas maneiras como, por exemplo, ao fazer uma compra, números de residências, telefones, enfim nos diversos momentos e ambientes sociais ela norteará e comprometerá significativamente as ações e necessidades do ser humano em sociedade.

Nesta perspectiva, a formação do educador do ensino Fundamental I segundo a Lei de Diretrizes e Bases da Educação (LDB/1996) em seu Artigo 62 ressalta que,

A formação dos docentes para atuar na educação básica far-se-á em nível superior, em curso de licenciatura, de graduação plena de universidade e institutos superiores de educação, admitida, como formação mínima para o exercício do magistério da educação infantil e nos cinco 5 (cinco) primeiros anos do ensino fundamental, a oferecida em nível médio modalidade normal. (BRASIL, 1996, p.29)

Desse modo percebe-se que, a formação docente é algo fundamental para o processo de ensino-aprendizagem, ou seja, ela se torna a passo primordial para que o profissional possa desempenhar o seu trabalho na área de matemática educativo e principalmente eficaz. Já que, a formação inicial proporciona os conhecimentos teóricos e pratica da ação pedagógica enquanto que, a formação continuada (res)significa a atuação docente oferecendo o suporte necessário para que o conhecimento e educação aconteça de forma eficiente.

Apesar de tais mudanças a Matemática não perdeu sua essência de ser uma disciplina que pode proporcionar ao discente, um conhecimento que oportunizará conhecer novos horizontes, deixando de lado seus medos e superando as dificuldades, reconstruindo a curiosidade de perceber a função dos números e, trazer em seu pensamento que, a matemática faz parte da vida humana, de suas relações sociais, sendo um instrumento indispensável para se viver em sociedade, a qual está diariamente envolvida em cada aspecto seja financeiro ou social e, os sujeitos precisam usá-la de maneira adequada e prática.

Sendo assim, é necessária a participação do(a) professor(a) preparado com uma formação consistente, a qual venha mostrar através de sua prática educativa-metodológicas ações diversificadas que desperte no discente, o querer aprender e consequentemente no decorrer das aulas resolver problemas simples, ou até mesmo complexos. Fato esse que, alguns educadores já fazem parte do seu cotidiano escolar, visto que, eles têm o prazer de 
ensinar e trazer o discente para dentro da matemática nos conteúdos, ou seja, muitos desenvolvem o seu trabalho na área de Matemática de forma brilhante. Neste sentindo,

Para desempenhar seu papel de mediador entre o conhecimento matemático e o aluno, o professor precisa ter um sólido conhecimento dos conceitos e procedimentos dessa área e uma concepção de Matemática como ciência que não trata de verdades infalíveis e imutáveis, mas como ciência dinâmica, sempre aberta à incorporação de novos conhecimentos (BRASIL, 1998, p.36)

Desse modo, o profissional do ensino da matemática nos anos iniciais do ensino fundamental I desenvolverá suas competências dentro da realidade escolar, de forma dinamizada e flexivelmente matemático, trazendo conceitos e vivências para dentro do processo de ensino-aprendizagem, gerando assim, fatores em que os próprios discentes possam ser os protagonistas, não ficando somente em meras transmissão de conteúdos programáticos.

Entretanto, para que isso ocorra com excelência precisa-se de mais políticas públicas voltadas para a formação de professores com ênfase no ensino de matemática, em prol da necessidade da qualificação do ensino, através da promoção de maiores formações continuada tanto para os atuais educadores como para os que estão assumindo agora essa função. Questionando-os sobre suas visões sobre o assunto, crenças e desafios, pois mais do que ensinar as estratégias para que se alcance um ótimo conceito matemático, é preciso conhecer e entender as perspectivas do professor enquanto profissional do ensino da matemática. Segundo Thompson (1997, p.40)

[...] crenças, visões e preferências dos professores sobre a matemática e seu ensino, desconsiderando-se o fato de serem elas conscientes ou não, desempenham, ainda que sutilmente, um significativo papel na formação dos padrões característicos do comportamento docente dos professores.

Neste sentido, o professor está a todo instante exposto as transformações, já que é um ser no mundo e para o mundo, afetando consequentemente o seu exercício na Educação Matemática, o seu modo de enxergar o discente como aprendiz e que ao mesmo tempo, pode lhe ensinar tanto. 
Ressaltar para eles, a relevância da matemática e principalmente atualmente, sendo que ela está cada vez mais presente, pois cotidianamente encontra-se os cálculos, algarismos, equações entre outros, e os discentes precisam ter o conhecimento que através dos conteúdos ensinados, questionamentos que lhes são impostos são fundamentais para o processo de formação integral do ser, na perspectiva humana e do saber matemático. Além de ser no Ensino Fundamental que tudo irá se construir no concreto, cujo pensamento lógicomatemático está se concretizando de forma mais profunda e que as influências do mundo moderno são essenciais na sua vida futura.

Nessa fase, será ao mesmo tempo, um pouco difícil e desafiador para o discente porque é um dos primeiros passos para vivenciar a matemática, porém, essa construção é crucial no processo de ensino-aprendizagem, uma vez que, traz consigo efeitos de grande importância no que se refere ao interesse de estudar e conhecer mais o universo abrangente da matemática.

Portanto, o professor precisa matematizar sempre, sejam em todos os conceitos, fórmulas, lembrando sempre que o discente está presente para aprender, mas além disso que, neste processo de aprendizagem trazer e vivenciar a matemática em seu dia a dia é imprescindível e, não só no âmbito escolar, já que essa disciplina mais do que um método é algo que ficará marcado para sempre na vida de cada sujeito, não importa quanto tempo passe, a matemática será sempre um subsídio promissor para sua trajetória estudantil e, de vida para além dos muros escolares.

\section{1- A MATEMÁTICA E O AMBIENTE SOCIAL E ESCOLAR}

É de relevância ímpar a formação continuada para os educadores enquanto construtores do saber, pois a prática docente requer como ponto de partida e de chegada um processo de formação eficaz, visando o aprimoramento do ensino da Matemática, e consequentemente professores preparados para a ação pedagógica no contexto escolar.

Para ser um bom educador é preciso portanto, articular teoria e prática a fim de selecionar os diversos saberes advindos de experiências cotidianas e saberes sistematizados. Essa prática a qual este estudo refere-se é uma ação refletida analisando os erros e buscando soluções para a construção de uma educação que desenvolva a autonomia do aluno. Preponderantemente, a relação entre ensino de Matemática e ambiente adequado é relevante, 
porque o ambiente social no qual a criança está inserida pode propiciar a aprendizagem. Cabe à escola e ao educador a função de estabelecer ao aluno um ambiente escolar de inspiração, de promoção da aprendizagem, e de integração do ser com o outro.

O ambiente escolar deve proporcionar ao aluno segundo Nacarato (2009, p.42), “a relação dialógica que se estabelece na sala de aula entre os alunos e entre estes o professor". Neste sentido a autora ressalta que o ambiente da sala de aula é o espaço que permitirá ao aluno o ato da fala, e do ouvir, como instrumentos de articulação entre a práxis, pois é a partir desse momento que o aluno passa a sentir-se membro ativo da escola produzindo e expondo as suas opiniões, participando das aulas, resolvendo os problemas matemáticos, nas brincadeiras, etc.

Com isso, esse conhecimento nos leva a refletir as seguintes questões: De que matemática não é somente cálculo, mas sim uma prática associada ao cálculo e a contextualização? Temos que retirar essa conclusão da mente do indivíduo que estudar matemática é uma tarefa ruim, cansativa, e sim mostrar que a matemática é algo precioso e que estará continuamente presente nas nossas vidas e nós, (enquanto seres humanos) temos que estar aptos para saber lidar com os diversos questionamentos que a sociedade tecnológica nos impõe pois, ao ensinar matemática estamos auxiliando ao indivíduo a construir um pensamento crítico.

Contudo, não pode-se afirmar que, o ensino da matemática é somente de responsabilidade do professor ou do aluno, mas também é tarefa dos pais a realização dessa formação, pois a escola e o professor sozinhos não conseguiram alcançar o objetivo, tem que haver ajuda dos pais exercendo o papel que lhes cabem à como incumbência de acompanhar perto os estudos dos filhos, de saber como anda suas amizades, se estão aprendendo mesmo, pois não ter esse comprometimento de estar presente na vida escolar pode prejudicar o andamento da aprendizagem e da educação de seus filhos.

Para que o ambiente escolar seja realmente aconchegante é necessário infraestrutura de qualidade, situações financeiras e administrativas bem estabelecidas, um apoio pedagógico voltado para uma educação de qualidade dentro da escola, para que o professor chegue a sala de aula e que os conteúdos de matemática sejam interessante e que chamem a atenção dos discentes é insubstituível que esse profissional disponha de uma formação dinâmica e de 
qualidade, como também materiais específicos para aquela determinada atividade, sala confortável e espaçosa, jogos matemáticos para despertar no aluno a curiosidade e etc.

Todos esses fatores devem sempre avaliados, analisando o que pode melhorar no âmbito escolar, tanto do lado dos pais, professor e escola. É essencial que todos trabalhem de mãos dadas lutando em prol de uma verdadeira e consistente Educação Matemática.

\section{2- AS DIFICULDADES E POSSIBILIDADES DO ENSINO DA MATEMÁTICA EM} SALA DE AULA

Muitos educandos que estudam matemática e principalmente os que estão no Ensino Fundamental acham essa disciplina muito difícil, veem como algo insuperável. Entretanto, é neste contexto de dificuldade de aprendizagem que surge a necessidade do professor de ter uma formação construída no saber ensinar ao outro levando a entender que a matemática é possível de se aprender.

A matemática se torna possível quando nos dispomos a estudá-la, em vez de nos acomodarmos nas operações simples de adição, subtração, multiplicação e divisão passarmos a apreciá-la de modo que ela estar envolvida diariamente com a vida do sujeito, seja com situações diárias como fazer compras, quanto pagar, o quanto vai receber de troco, descontos, etc.

É a partir dessas interações com o meio que o aluno irá ampliar e adquirir novos conhecimentos matemáticos, sem falar que a matemática contribui de fato para um raciocínio lógico ao qual requer do indivíduo a organização do pensamento, concentração, análise que já podemos chegar ao ponto final, devido à construção de conhecimentos nas series anteriores.

No entanto, as metodologias utilizadas para o ensino dessa disciplina nas escolas precisam se recompostas, uma vez que o professor se baseia apenas em trabalhar matemática com simples memorização. Segundo Maccarini (2010, p. 32) "quando o ensino dessa disciplina se baseia na simples memorização de cálculos, formulas, e procedimentos mecânicos de resolução, ele não favorece, adequadamente, desenvolvimento do raciocínio lógico do indivíduo".

Assim sendo, para que a construção do raciocínio logico aconteça é necessário que o professor utilize métodos que favoreçam o desenvolvimento, associando as atividades 
escolares com as experiências cotidianas, pois é a partir disso que o educador poderá elaborar estratégias com base nas vivências que o aluno presencia ou já passou. Como afirma Maccarini (2010, p.26)

O professor exerce um papel fundamental no desenvolvimento e na relação da criança com o conhecimento matemático, na medida em que valoriza e aproveita as experiências já vivenciadas por ela, fazendo as devidas intervenções e proporcionando a aplicação desses conhecimentos.

Deste modo, as experiências que a criança traz precisam ser consideradas e levadas em consideração para serem trabalhadas, como também é necessária a seleção dos conteúdos, pois devem ser conteúdos que sirvam para a atuação do sujeito em sociedade, neste caso, a formação do professor é relevante para se obter êxito em sua pratica educativa.

Vale ressaltar que, é importante que o professor tenha intencionalidade naquilo que ele vai repassar para os discentes, pois não adianta ter uma formação excelente e na hora de colocar em prática tudo que foi planejado, não saber como desempenhar e só transmitir por transmitir uma aula sem nenhuma mediação, é preciso que haja uma estratégias metodológicas eficazes nas aulas de matemática, as quais respondam diariamente as seguintes indagações por parte do docente, de qual é a melhor forma para se trabalhar uma atividade que traga a matemática como forma prazerosa para o discente, oportunizando uma melhor aprendizagem? Sem esquecer de estar analisando no planejamento das aula, o porquê, para que e o como transmitir um determinado conteúdo de matemática, almejando somente o agora ou que aquela internalização promova um saber matemática para a vida do discente? São fatores que, analisados e praticados no ambiente escolar, permearão uma formação de professores competentes para responder tais questões, além de traças meios educacionais para chegar à uma educação em todas as dimensões e de um ensino de matemática de qualidade no Ensino Fundamental I.

\section{CONSIDERAÇÕES FINAIS}

A formação docente portanto, é considerada como artificie principal para a construção de um saber sistematizado pelo o discente, não somente no âmbito do ensino da matemática, mas em todos os aspectos educacionais, sendo que, sem ela a qualidade e humanização em prol de um ensino emancipatório e diversificado, na produção de aprendizagens significativas fica ainda mais longe de ser vivenciado na escola pública. 
A construção deste artigo para tanto, foi relevante para nosso processo de formação enquanto futuras docentes e servirá como referência para sabermos como exercer nossa profissão em sala de aula, visando um ensino de matemática significativo, que transforme a realidade do discente, mais que seja o assunto vivido na identidade e formação do docente.

Pode-se afirmar que, este estudo foi gratificante, além de responder a indagação iniciada neste estudo enfatizando a formação dos professores para trabalharem com o ensino da Matemática nos anos iniciais do Ensino Fundamental I articulado com sua pratica pedagógica para despertar no discente o interesse em estudar matemática.

Contudo, cabe a escola estabelecer ao professor uma formação continuada, e aos alunos novas metodologias para que eles superem essa terrível impressão de que a matemática é uma disciplina ruim, mas que passem a considerar a matemática com algo essencial para a vida em sociedade e que de uma forma ou de outra não tem como viver num mundo tão tecnológico sem situações que envolva a Matemática.

Acredita-se ainda que, é possível construir um novo conceito sobre a Matemática levando em consideração que ela faz parte de nosso dia-a-dia e que precisamos de mais profissionais de qualidade para trabalhar a matemática, de forma motivadora e que deixe naquele que a estuda um gosto de querer aprender sempre mais.

\section{REFERÊNCIAS}

BRASIL, Lei no 9394. Lei de Diretrizes e Bases da Educação Nacional. Brasília: Congresso Nacional, 1996.

BRASIL. Secretaria de Educação Fundamental. Parâmetros curriculares nacionais: Matemática / Secretaria de Educação Fundamental. Brasília : MEC / SEF, 1998. Disponível em <http://portal.mec.gov.br/seb/arquivos/pdf/livro01.pdf > . Acesso em: 20 agosto 2017.

MACCARINI, Justina Motter. Fundamentos e metodologias do ensino de matemática. Curitiba: Editora Fael, 2010.

NACARATO, Adair Mendes. A matemática nos anos iniciais do ensino fundamental: tecendo fios do ensinar e do aprender. - Belo Horizonte: Autêntica Editora, 2009

TOLEDO, Marília Barros de Almeida. Teoria e prática de matemática: como dois e dois. Volume único: livro do professor. - 1. ed. São Paulo: FTD,2009 
